\title{
Heavy Duty Hybrid Vehicle Evaluations in Utility Fleet Applications
}

\author{
Jordan W. Smith, P.E., Engineering Lead*
}

\begin{abstract}
Southern California Edison Company (SCE) has shown a commitment to deploying vehicles in its fleet that meet or exceed emissions standards, emit lower greenhouse gases, and reduce use of petroleum. This has been best demonstrated by operating the nation's largest electric vehicle utility fleet to conduct daily business, as well as demonstrations of hydrogen, fuel cell, and hybrid vehicles. SCE has also for many years been evaluating heavy-duty hybrid technology for use in its fleet. Heavy duty vehicles use a large amount of fuel, and thus even a small percentage savings is significant in terms of total amount of fuel displaced. SCE's fleet uses millions of gallons of fuel per year, much of that being used to run trucks. In addition, the purchase price premium associated with hybrid vehicles is potentially much lower on a percentage basis than with light-duty vehicles. Recently, SCE took part in a national consortium to specify and order a limited number of prototype Class 6 hybrid-electric utility trucks. In conjunction, SCE developed extensive test and evaluation procedures using sophisticated methods and equipment. SCE received its truck in December of 2006. This paper will detail SCE's evaluation procedures and philosophies and give some details on preliminary experiences.
\end{abstract}

Keywords: Hybrid, heavy-duty, fleet

\section{INTRODUCTION}

Southern California Edison (SCE) and its Electric Transportation Department have a history of working with partners and with other stakeholders to support and advance the use of electric-drive vehicles (EVs). Electric-drive vehicles use clean and efficient electrical energy for all or part of their total required energy to drive and conduct other needed work functions. The purpose of SCE's evaluation of electric and hybridelectric vehicles, battery chargers, batteries, and related energy efficient devices is to educate and advise its customers, to make informed purchase decisions for its own fleet, to support safe and efficient use, and to minimize potential utility system impacts from using grid energy as a transportation fuel. In today's world that has also come to mean an associated reduction in petroleum use and greenhouse gas reduction.

Because of SCE's recognized expertise, manufacturers have often solicited its help to evaluate advanced technology products in a real-world environment. In 1989, SCE worked with Chrysler to demonstrate a minivan conversion and initiated the design of General Motors' G-van passenger-van conversions. The acquisition of fifteen G-vans began SCE's initial electric vehicle fleet in the modern era, as did the formation of its Electric Transportation Department (ET). This

*Electric Transportation Department Southern California Edison Company

265 North East End Avenue, Pomona, California 91767

Telephone: (909) 469-0250, Fax: (909) 469-0319

(c) 2008 WEV Journal department, one of the first in the nation of its kind, brought together engineers, scientists, and regulatory specialists in electric vehicles, buses and trains, battery systems, renewable energy production, and electric utility infrastructure.

In an effort to ensure the success of its EV fleet, the EV Technical Center (EVTC) was created in 1993 in Pomona, California as the department's technology arm to provide answers to those who questioned the visions and capabilities of electric drive. The EVTC, which is dedicated to studying utility-related EV issues, was selected in 1996 as one of just two U.S. Department of Energy (DOE) test sites in the nation for evaluation of EV baseline performance, reliability, and fleet operation. The Center serves original equipment manufacturers, fleet purchasers, academics and the public as the most complete and advanced facility of its kind. The facility includes extensive and sophisticated battery and charger laboratory testing equipment, light and heavy vehicle service facilities, machine shop, six vehicle testing bays, and four dedicated EV maintenance bays staffed with OEM-qualified technicians. In addition, the EVTC conducts tests on local world-recognized test loops. The EVTC was ISO registered in 2000 .

\section{SCE'S HYBRID TROUBLEMAN TRUCK}

In the mid- to late-1990s SCE worked with some truck manufacturers to investigate heavy-duty hybrid trucks. Like other large utilities nationwide, SCE operates thousands of trucks in its fleet to conduct its operations

Heavy -Duty Hybrid Veicle Evaluations in Utility Fleet Applications 
and provide services to its customers and spends millions of dollars on fuel to do so. Despite the huge potential savings promised by such platforms and the interest provided by utilities, who are large customers of the manufacturers, all the programs were abandoned. In 2001, the EVTC began work on its own to convert one of its Troubleman Trucks into a plug-in hybrid. Completed over a period of eighteen months, the truck was delivered to the fleet for demonstration in January 2004. The truck offered ground-breaking features such as 15-mile electric driving range on grid-supplied energy, battery-powered electro-hydraulics, and export power panel providing $15 \mathrm{~kW}$ electrical power. Workers using the truck reported that it was just as capable to do work as their conventional trucks and was easier to use, quieter, and cleaner [1].

\section{HYBRID TRUCK USERS' FORUM}

Nationwide demand from electric utilities wanting to use clean fuel that they provide to power their vehicles and reduce fuel use and costs, fueled by interest generated from SCE's hybrid truck demonstration, led to formation of the Hybrid Truck Users' Forum, moderated by Calstart/Weststart. The Forum formed a Utility Working Group (one of four special groups in HTUF) in 2002 consisting of more than 20 utilities nationwide, including SCE.

The HTUF Utility Working Group issued a request for proposals for a heavy-duty Class 6/7 hybrid utility trouble-truck to truck manufacturers in Spring 2004, and a winner was announced in October 2004. The winning team formed a partnership between International Truck and Engine Corp., Eaton Corp., and Altec, Inc.

The required performance parameters for the truck included:

o Maintain base vehicle dimensions, performance, and core capability

o Cause no decrease in reliability, durability, reparability

o Significant increase in fuel economy - over $50 \%$ desired

o Meet or exceed 2010 EPA emissions

standards

o Overall lifecycle costs less than or equal to diesel equivalent truck

o Engine-off hydraulic power for lift and tools

o Field power generation up to $25 \mathrm{~kW}$

o Power panel for electric tools and accessories o Noise levels significantly lower than diesel truck

Fleets from 14 utilities placed orders for 25 preproduction units to begin delivery by the end of 2005 . SCE received its truck (the $23 r d$ unit produced) at yearend 2006.
Key features of the truck included:

o Satisfaction of SCE BC 325 specification

o Eaton's integrated automatic manual transmission

o International DT466 diesel engine at $225 \mathrm{hp}$

o $44 \mathrm{~kW}$ electric motor/generator in a parallel hybrid design with the AMT

o Regenerative braking to increase efficiency and reduce brake wear

o $25 \mathrm{~kW}$ mobile electric power panel for base

power, electric tools and accessories

o Li-ion battery at $1.9 \mathrm{kWh}, 340 \mathrm{~V}$

o 1 to 2 hours stationary intermittent

operation with less than 8 min engine recharge

o Base vehicle dimensions, performance, and

core capability maintained

oSignificant fuel savings potential - up to $60 \%$ reduction

o Possibly meet 2007 EPA emissions standards on a drive-cycle equivalent basis

o Overall lifecycle costs expected to be less than or equal to diesel

o Engine-off hydraulic power for lift and tools o Noise levels significantly lower than diesel truck in stationary applications

Scientific test results from a recognized national laboratory on a prototype truck showed up to $150 \%$ improvement in fuel economy and $60 \%$ reduction in petroleum fuel used. Carbon monoxide emissions were reduced up to $90 \% ; \mathrm{NO}_{\mathrm{X}}$, up to $60 \%$; $\mathrm{PM}$, up to $40 \%$; and hydrocarbon, up to $80 \%$ over baseline diesel on identical duty cycle tests. The greatest factor in these impressive results is the fact that the diesel engine shuts down during stationary operations, saving fuel and saving workers from harmful fumes and noise. ET conducts its own independent scientific tests on advanced technology vehicles, and these results will be released for publication when complete.

After the EVTC took delivery of the truck in 2006, it was subjected to a full performance, safety, and reliability evaluation in conjunction with SCE's Transportation Services Department (fleet vehicle management) before delivering to the Transmission and Distribution Department (utility services) for a monitored fleet assessment. Data will be shared with other HTUF participants and the manufacturers in order to understand and master the technology and improve production versions.

International Truck and Engine Corporation has announced that full commercial production capability of this hybrid platform has been achieved in 2007. Given current tax credits and fuel savings, along with expected maintenance savings, these hybrid trucks are potentially competitive with conventional diesel in lifecycle cost. Further advancements are expected with hybrid drive trains in the near future with plug-in technology combined with electric and other alternate 
fuels to provide increased savings. SCE and the Electric Power Research Institute (EPRI) are working with other utilities to build plug-in hybrid trouble trucks in the Ford Super Duty class, which could potentially fit many more applications than the Class 6 platform. A prototype could be delivered to SCE as soon as early next year.

\section{DEVELOPMENT OF EVALUATION PROCEDURES}

At the EVTC, procedures are developed in accordance with the EVTC's established ISO 9001:2000 Quality Manual. Illustrated in Figure 1, the process begins with establishing procedure requirements. The requirements are typically based on evaluating the device as delivered, demonstrating its reliability, and then implementation in service. A Procedure Design Team processes such input, establishes success criteria and constraints, and produces a preliminary test plan which is subjected to an initial design review. Design reviews are attended by engineering staff and management, and the product is scrutinized to make sure criteria are satisfied. If approved, the plan is developed into a preliminary procedure, which then undergoes a simulation. Simulation may consist of computer modeling of the procedure, or, for example, driving trials of a potential test cycle. Simulation is followed by a preliminary review of the results and comparison to criteria and constraints. An initial draft procedure is then published and validated through a process of certification with an official testing organization, which could be internal or external. If successful, a final design review is then conducted to make sure the procedure accomplishes the original intentions and all safety and uncertainty requirements are addressed.

\section{HEAVY-DUTY HYBRID VEHICLE EVALUATION PROCEDURES}

The evaluation of heavy-duty HEVs, PHEVs, and EVs in utility fleet operation has three main components. The first part is a performance evaluation, or performance characterization, which includes measuring the operating parameters of the vehicle, battery, and charger. This serves to both validate manufacturers' claims, compare to similar and existing vehicles, and to document baseline performance that may change as the vehicle ages. Baseline measurements of the traction battery's capacity and power capabilities are taken. The efficiency and system impact of the charger is characterized. Braking, acceleration, and gradability of the vehicle are evaluated, and then road tests are performed in different scenarios and configurations to determine fuel economy, demonstrate functionality and effectiveness, and prove safety of operation. It is vital that a conventional comparable vehicle is run through the same tests in the same fashion in order to make valid comparisons. Also, it is preferable to run parallel battery tests in the lab, as such tests can be run in an accelerated manner. Battery and vehicle tests are calibrated to ensure validity. An overview of the tasks included in the evaluation procedures, and the order in which they are performed is shown in Figure 2.

The second component of the test process is a period of accelerated driving schedules to evaluate the reliability of the vehicle. This period consists of extensive driving and operation in a manner that simulates real field duty. In this way, any potential defects are identified and corrected before the vehicle is put into users' hands. In addition, the data collected in these simulations is used to compare to actual duty

The third part of the complete evaluation is integration into the SCE fleet while documenting capabilities and impact. This last aspect of testing provides further understanding of fuel economy and reliability in realworld operation and of user acceptance in a fleet application. It also helps to validate and adjust EVTC test procedures.

\subsection{HEAVY-DUTY VEHICLE PERFORMANCE CHARACTERIZATION PROCEDURES}

Performance characterization includes traction battery capacity and charger tests (if a plug-in hybrid), hybrid and electric mode performance evaluations, hybrid mode drive tests, and an electric mode range test (if capable). In addition, the performance evaluation includes dynamometer testing of vehicle performance and emissions, an analysis of auxiliary (12 volt) systems, and a safety and compliance test. These procedures are bracketed by an initial check-in procedure and a final inspection before continuing on to any further testing.

\subsubsection{Nameplate Data Collection and Vehicle Turnkey Inspection}

This initial aspect of testing includes nameplate data collection and vehicle turnkey inspection, weight documentation and fuel measurement. The nameplate data, such as vehicle make, model, Vehicle Identification Number (VIN), and mileage is recorded. The turnkey inspection involves ensuring that the vehicle is safe for operation. This includes turning on and verifying the safe operation of lights, gages, windshield wipers, horn, seat belts, and any other accessories the vehicle may have. The engine compartment is checked for fluid leaks; oil and water levels are viewed; the integrity of all belts and hoses are visually assessed.

\subsubsection{Traction Battery Capacity and Charger Tests}

If possible, battery capacity tests are performed before the vehicle tests to determine the actual and useable battery capacity following the United States Advanced 


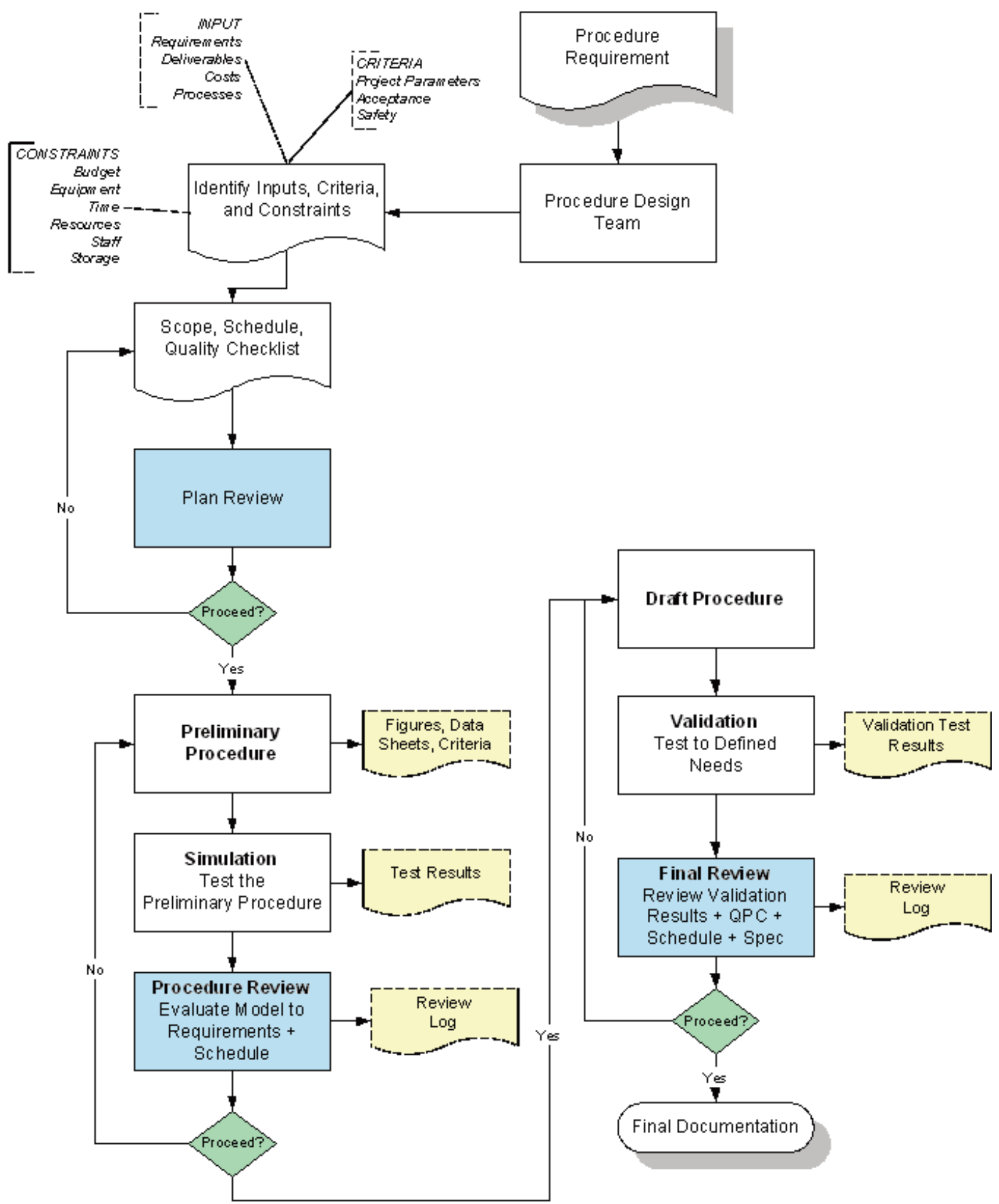

Figure 1: Procedure Development Process 


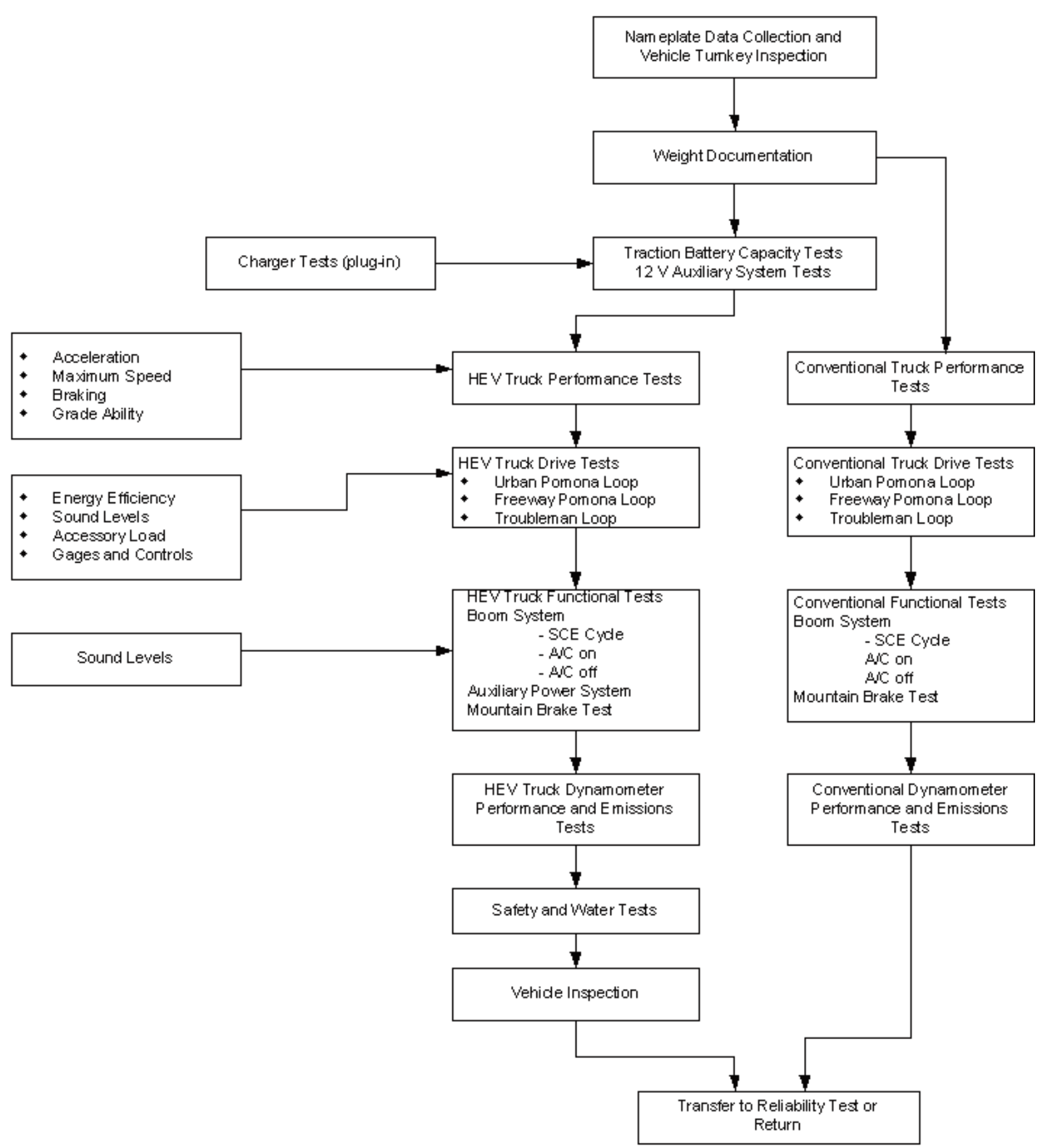

Figure 2: Test Plan Flow Chart

Battery Consortium (USABC) procedure [2] for constant current discharge tests, along with other appropriate tests for hybrid batteries. Peak power tests are also conducted, and also any specified hybrid protocol cycles. A Peukert Curve is constructed to show the effect of discharge rate on capacity. The performance of the battery charger is characterized to identify utility grid impact. Stand-by and auxiliary loads are also evaluated.

Once a system is set to record traction battery current

and voltage from the vehicle Controller Area Network (CAN) bus, the testing can begin. First, fully charge the traction battery using the vehicle's charging system or the battery manufacturer's charging algorithm. Take the pack off charge at least 30 minutes before the start of the discharge tests. Then connect a battery cycler to the traction battery and record the initial open circuit pack voltage, average pack temperature and ambient temperature. Pack temperature can be obtained either through the vehicles diagnostic system or from several 
thermocouples placed throughout the pack. Discharge the traction battery at a constant current until the cutoff voltage is reached. Record pack current, pack voltage, ampere-hours (Ah), kilowatt-hours (kWh), module voltage, and module temperature at 10-second intervals throughout the discharge.

The battery discharge tests are based on the USABC guidelines for constant current discharge and are performed at a starting battery temperature of $23^{\circ} \pm$ $2^{\circ} \mathrm{C}$. Groups of three constant current discharge cycles at each of $\mathrm{C} 3 / 3, \mathrm{C} 2 / 2, \mathrm{C} 1 / 1$ and again $\mathrm{C} 3 / 3$ amperes are performed. At the end of each cycle, open circuit pack voltage (taken at least 30 minutes after the end of the discharge test), ambient temperature, average pack temperature, voltage difference at the stop condition, lowest module voltage at the stop condition, DC amperehours out, and DC kilowatt-hours out are measured and recorded. The discharge testing is repeated until the C3/3 capacity is stable within $2 \%$ for three consecutive discharges.

\section{Charger Tests}

Charge the vehicle using the vehicle's charger and record the $\mathrm{AC} \mathrm{kWh}$ input into the charger and the DC $\mathrm{kWh}$ from the charger to return the traction battery to $100 \%$ SOC. Determine the percent overcharge by dividing the DC $\mathrm{kWh}$ returned to the battery by the DC $\mathrm{kWh}$ discharged from the battery. Plot the discharge time versus discharge current on a logarithmic scale to obtain the Peukert curve. Compare the results of these tests to the EPRI Infrastructure Working Council (IWC) Electric Vehicle charging recommendations [3].

Measure sound levels of the charger while the vehicle is charging in a quiet location. Use a sound level meter to measure charger noise intensity at various power levels from a distance of one meter from the charger at a height of one meter.

Connect instruments to measure the load on the 12 volt system at rest, while charging, and while driving. The auxiliary load stand-by test measures the load on the auxiliary $(12 \mathrm{~V})$ system while the vehicle is parked and all systems are off, for a period of at least 12 hours. This measures load on the auxiliary system when the vehicle is parked. It's important to understand the ability of the $12 \mathrm{~V}$ system to function after sitting for a long period of time and to assess when and at what level the battery is being charged. This is an issue of reliability for utility fleets.

\subsubsection{Hybrid and Electric Mode Performance and Drive Tests}

Performance testing includes evaluation of the vehicle's acceleration, maximum speed, braking and gradability in both hybrid (HEV) and electric (EV) modes. In HEV mode performance tests the engine is operating and the payload is one driver and required test equipment. In $\mathrm{EV}$ mode performance tests the engine is disabled and the tests begin with the traction battery at $100 \%$ State of Charge (SOC). The payload includes one driver and required test equipment.

The vehicle fluid levels, coolant, brake fluid, etc., are checked at the beginning of each day of testing. The tire pressure is checked and inflated to the maximum tire pressure indicated on the tire sidewall using a calibrated tire pressure gage. This is done once per day, at a regular time and standard temperature. Record the odometer reading and starting ambient temperature.

Test and record acceleration from a stop to maximum speed, and record the times for 0-48 km/h (0-30 mph) and 0-97 km/h (0-60 $\mathrm{mph})$ acceleration in both HEV and EV modes. Repeat the procedure in opposite directions to average the effects of wind and grade. Record the maximum speed achieved during each of the acceleration tests and report the average in both modes of operation.

Measure the vehicles braking ability from a steady 40 $\mathrm{km} / \mathrm{h}(25 \mathrm{mph})$ in opposite directions to determine the average braking distance and cancel any effects of wind or grade. The battery SOC must be in the range of $40 \%$ to $70 \%$ in each trial, as a fully charged traction battery has a limited ability to accept regenerative braking energy.

There are two types of grade ability: the maximum, or stall grade and the maximum speed on a particular grade. Use a stationary fixture to determine the maximum grade for both $\mathrm{HEV}$ and $\mathrm{EV}$ mode. With the vehicle on the grade, try to drive up. Increase the grade until the vehicle will just barely move up, this is the maximum grade. Next, determine the maximum speed on a $4.5 \%$ grade for HEV mode only. This is done by driving the vehicle westbound on the Kellogg grade on I-10 west of Pomona, CA and recording the maximum sustainable speed.

Follow the same test set-up procedures and checks for HEV mode drive tests as described for the hybrid and electric performance tests. Test the vehicle on both urban and freeway drive cycles. Conduct the Urban Pomona Loop in four vehicle test configurations, shown below as UR-1 through UR-4. The Urban Pomona loop drive test has a distance of 31.1 kilometers (19.3 miles) and includes approximately 50 stop signs and traffic lights.

UR-1 Minimum payload (driver only) with no auxiliary loads.

UR-2 Minimum payload (driver only) with auxiliary loads on: fans, lights, heater, $\mathrm{A} / \mathrm{C}$ and radio.

UR-3 Vehicle loaded to maximum legal weight limit with no auxiliary loads

UR-4 Vehicle loaded to maximum legal weight limit with auxiliary loads on 
The Urban Pomona Loop Elevation Profile is shown in Figure 4.

Conduct the Freeway tests in the same load configurations as the Urban Pomona Loop tests; designated FW-1 through FW-4. The Freeway Pomona Loop has a total distance of 59.9 kilometers (37.2 miles). Conduct both sets of tests in a manner compatible with the safe flow of traffic for the determined routes. The Freeway Pomona Loop is shown below in Figure 5.

Drive the vehicle on the Urban and Freeway Pomona Loops with the engine operational and the specified payload. Start the tests with a full fuel tank and the traction battery at $100 \%$ SOC (for plug-in). Measure exact fuel usage with a fuel flow meter. Determine energy usage in equivalent fuel gallons: this includes the amount of liquid fuel used plus the "fuel volume equivalent" of electrical energy (in $\mathrm{AC} \mathrm{kWh}$ ) provided by the utility grid to recharge the traction battery to $100 \%$ SOC after the drive. Determine the electrical equivalent by converting the AC grid energy used to recharge the battery to a fuel equivalent based on the conversion recommended by the Society of Automotive Engineers [4].

\section{o $3,412 \mathrm{BTU} / \mathrm{kWh}$ \\ o LHV of diesel fuel}

Determine the energy efficiency using the equivalent fuel gallons on both a miles per equivalent gasoline gallon (mpge) and in $\mathrm{kWh}$ per mile ( $\mathrm{kWh} / \mathrm{mi})$ basis.

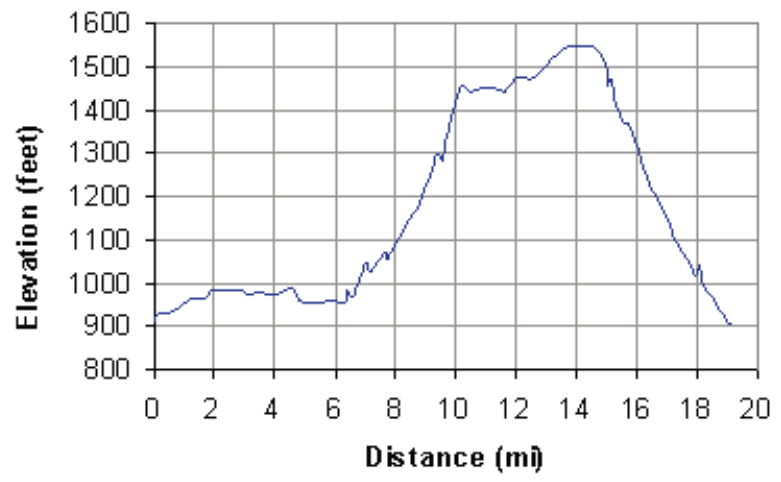

Figure 4: Urban Pomona Loop Elevation Profile

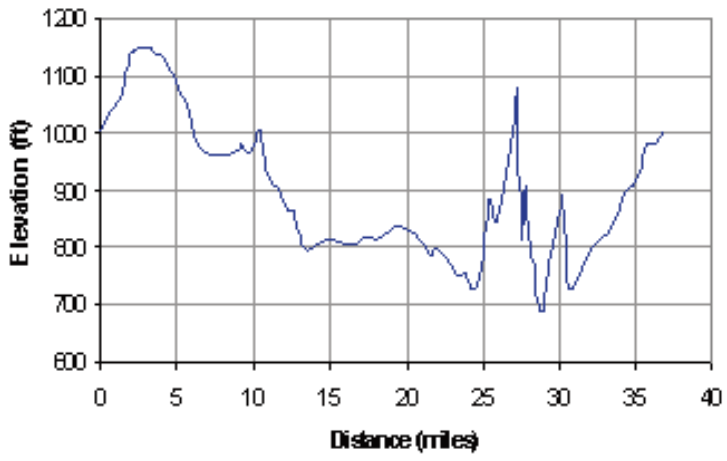

Figure 5: Freeway Pomona Loop Elevation Profile
Repeat each test until the fuel consumption per mile differs by less than $5 \%$ compared to the previous result. Report the average of the final two tests.

Measure the interior sound levels in the vehicle cabin during one portion of each of the Urban and Freeway Pomona Loops with the engine enabled. Report the recorded plots from the meter and average sound levels.

Check all gages and controls to verify proper operation. This includes cross checking the final fuel flow meter data with fill station readings and dashboard fuel gage. Observe the traction battery state of charge during the tests. A complete evaluation of the SOC gage is done during the all-electric range tests. Asses the response of the accelerator pedal, effectiveness of shift lever, ease of use of the engine control and accessory switches, and legibility of all gages. Subjectively evaluate and record the driving characteristics of the vehicle during testing. This evaluation includes:
o Handling
o Steering
o Braking
o Ability to conform to traffic conditions
o Driver comfort and confidence

Conduct a mountain drive braking test to measure and verify electrical and friction braking systems. This can include thermal instrumentation of brake linings.

\subsubsection{PHEV and EV All-Electric Range Tests}

Perform the all-electric range tests on the Urban Pomona Loop; if the vehicle is not capable of driving this loop in all-electric mode, then a less demanding test loop, such as the HEV Utility Trouble Truck Loop may be used. The elevation profile of the HEV Utility Trouble Truck Loop is shown in Figure 6.

Follow the same test set-up procedures and checks as described for the hybrid and electric performance tests. The payload for these tests is one driver and required test equipment only. Before the test, record the pack voltage, odometer reading and ambient temperature. Drive the vehicle along the Urban Pomona (or HEV Trouble Truck) Loop in a manner compatible with the safe flow of traffic. Record the following data at fivemile intervals: state-of-charge, pack voltage, DC kWh, and odometer readings. The end of the test is determined by a warning signal provided to the driver by the vehicle, before diminished performance prevents the vehicle from operating safely in traffic. This signal light typically should illuminate between $15 \%$ and $20 \%$ SOC.

At the end of the test, record the odometer reading, state-of-charge, ambient temperature, DC kWh, and pack voltage thirty minutes after the end of the test. Use detailed notes of any driving deviations and mapping software to record the distance traveled to the 


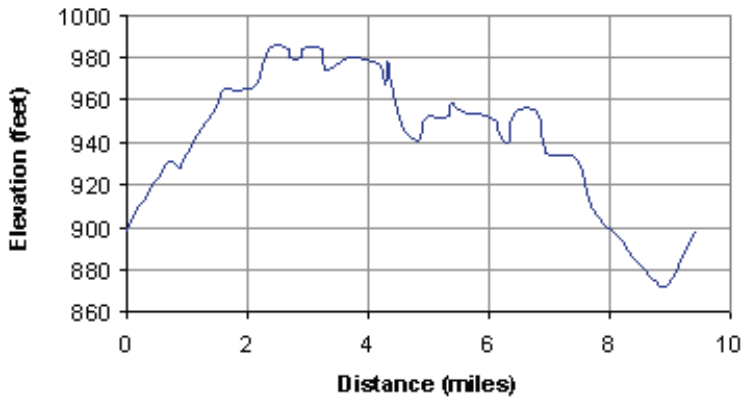

Figure 6: HEV Utility Trouble Truck Loop Elevation Profile

nearest tenth of a mile. Repeat the test until the range result is within $5 \%$ of the previous result. Report the average of the final two tests.

While driving the range tests, record the distance traveled according to the vehicle odometer corresponding to intervals on the vehicle's state-ofcharge meter (typically $3 / 4,1 / 2,1 / 4$ and Empty). At the end of the trip, record the total number of miles driven. An ideal state-of-charge meter yields a chart similar to Figure 7 for a vehicle with a range of $32 \mathrm{~km}$ (20 miles), and the vehicle achieves maximum range when the state of charge meter indicates "Empty".

A plot similar to Figure 7 is generated during charging using the DC energy supplied by the charger (instead of miles) versus the level on the state-of-charge meter; this provides a representation of state of charge versus energy delivered and charging time.

Fully recharge the traction battery and record the electrical energy usage in $\mathrm{AC} \mathrm{kWh}$ to determine the $\mathrm{AC}$ $\mathrm{kWh}$ per mile efficiency. This energy used, divided by the total number of miles driven, yields the $\mathrm{AC} \mathrm{kWh}$ per mile efficiency of the vehicle.

Measure the sound levels in the vehicle while operating in EV mode from approximately ear level on the passenger seat using a sound level meter. Record sound levels during a portion of one Urban Pomona Loop with the windows rolled up and all accessories turned off. Note any external noises from sources other than the test vehicle that are loud enough to register on the sound meter. Report the average sound levels and plots of recorded data from the test.

Evaluate the vehicles' performance and emissions using a dynamometer in accordance with the SAE J2711 procedures. In addition, run the INRETS URB 1 drive cycle. This test cycle was developed by the French research group INRETS based on measurements of vehicles in actual urban driving scenarios (Figures 8, 9). This drive cycle lasts about 12 minutes and covers 4.2 $\mathrm{km}(2.6 \mathrm{mi})$ with 13 stops and nearly three and a half minutes of idle time. This cycle is important because

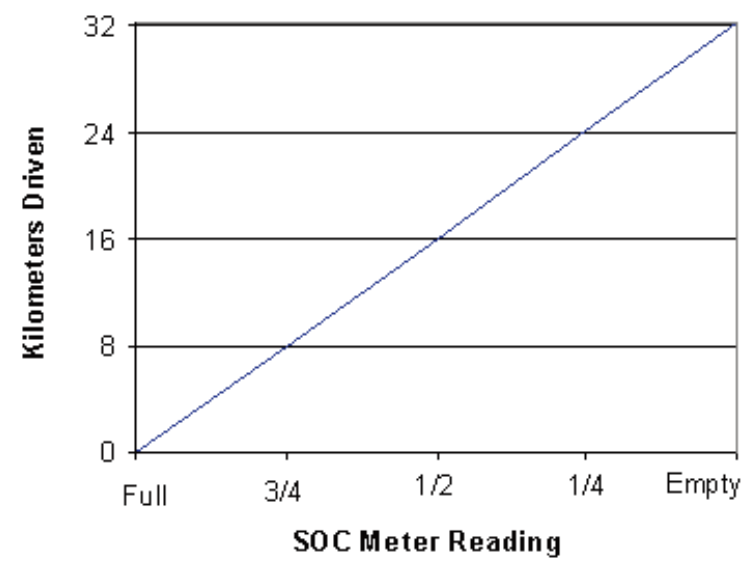

Figure 7: Ideal SOC Meter Correlation

EVTC has extensive laboratory data using this test cycle, and correlations can be made with vehicle and lab testing.

\subsubsection{Safety and Compliance Tests}

The safety and compliance tests include a water safety test, ground clearance measurement, and confirmation of safety systems. The water chassis leakage test determines the ability of the vehicle to safely endure water conditions without hazard. This test determines if the amount of leakage current from battery to chassis and from chassis to ground after the vehicle is driven through a sprayed water test area is within safe levels. Information gained from checking the ground clearance and safety systems is used to train drivers in safe vehicle operation.

Prior to driving the vehicle onto the standing water test track perform a preliminary vehicle inspection to check the following items:

o The vehicle's SOC meter reads full or $100 \%$ (plug-in)

o There are no visible electrical hazards,

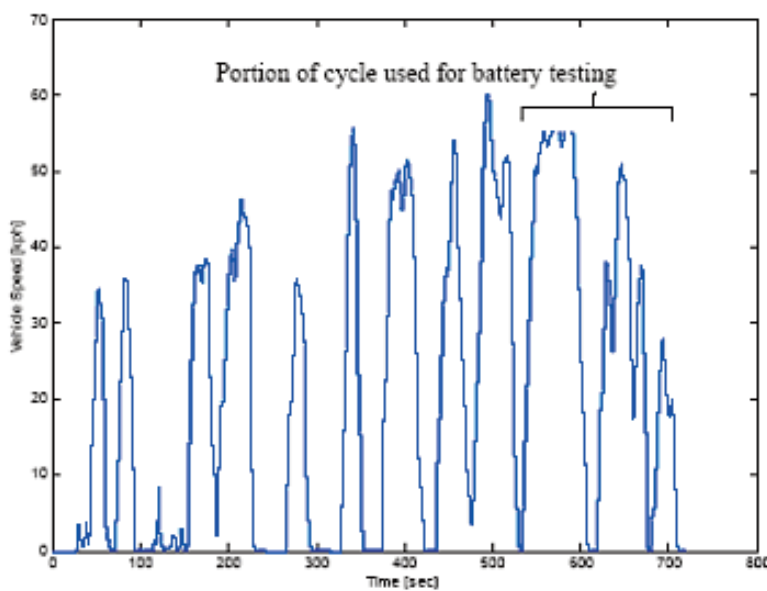

Figure 8

Heavy -Duty Hybrid Veicle Evaluations in Utility Fleet Applications 


\begin{tabular}{|l|c|}
\hline Cycle Time & $719 \mathrm{~s}$ \\
\hline Distance & $4.19 \mathrm{~km}$ \\
\hline Maximum Speed & $16.39 \mathrm{~m} / \mathrm{s}$ \\
\hline Average Speed & $5.81 \mathrm{~m} / \mathrm{s}$ \\
\hline Maximum Acceleration & $2.44 \mathrm{~m} / \mathrm{s}^{\wedge} 2$ \\
\hline Average Acceleration & $0.69 \mathrm{~m} / \mathrm{s}^{\wedge} 2$ \\
\hline Maximum Deceleration & $-4.39 \mathrm{~m} / \mathrm{s}^{\wedge} 2$ \\
\hline Average Deceleration & $-0.71 \mathrm{~m} / \mathrm{s}^{\wedge} 2$ \\
\hline Idle T me & $194 \mathrm{~s}$ \\
\hline Number of Stops & 13 \\
\hline Stop Frequency & $3.11 \mathrm{stop} / \mathrm{km}$ \\
\hline
\end{tabular}

Figure 9. INRETS URB1 Test Cycle

including loose battery connections or wires on the exterior of the vehicle that present a possible hazard.

Before the start of the test, record the ambient temperature, humidity, test start time, date, and vehicle number. The water test involves driving the vehicle slowly over a sprinkler setup in a test area several times to completely wet the underside of the vehicle. Record any abnormalities or failures that occur during testing. After the underside of the vehicle is completely wet, move the vehicle to the charging area and start the charging process (plug-in). Within five minutes, measure and record the following:

o The battery leakage current from battery to chassis. The current should be less than 0.5 Measurement Indication Units (MIU).

o The battery leakage current from chassis to ground. The current should be less than 0.5 $\mathrm{mA}$.

Additionally, record any failures or abnormalities that occur during vehicle charging.

Measure the minimum ground clearance and the height of the front and rear bumpers in order to determine the maximum angle of approach and departure. Use this measurement to compare to conventional vehicles used in similar applications. Verify the safe operation of any emergency switches on the vehicle.

\subsubsection{Vehicle Inspection and Transfer}

Conduct a walk though inspection of the vehicle with a Transportation Services Department (TSD) engineering team before transferring the vehicle to reliability or fleet testing. Transportation Services has governance over SCE's transportation fleet, including vehicle replacement decisions, acquisition and disposal and garage services. They also provide commercial and defensive driver training. TSD evaluates the vehicle for ease of use and becomes familiar with the vehicle for driver training and fleet operation purposes.

\subsection{Reliability Test Procedure}

After performance characterization, schedule the vehicle for reliability testing for three months, followed by one year of fleet trials. The reliability tests include three months of daily driving and evaluating the energy usage and controls and display systems of the vehicle.

As described previously for the Performance Characterization Procedure, record all nameplate data, and serial numbers for the vehicle and all test equipment. Note the version of software and hardware and any component changes since the performance characterization tests.

Log all fuel usage and the odometer reading at fill-ups and meter the utility connection to record electrical AC energy usage daily.

The completion of Reference Performance Tests (RPT's) are on an $8050 \mathrm{~km}$ (5000-mile) or quarterly basis thereafter until the end of the reliability trials. The baseline performance test and RPT are very similar to the Performance Characterization Procedures described previously. If the performance characterization procedure is performed within thirty days of reliability testing, that will serve as the baseline test. The reference performance tests (RPT's) performed at intervals throughout the reliability testing includes the performance tests, all-electric range tests, HEV fuel economy tests, battery capacity tests, and dynamometer performance and emissions tests. Conduct the tests in the same manner as described in the Performance Characterization Procedures.

A designated driver drives the vehicle each normal work day on the Urban Pomona Loop, Freeway Pomona Loop, or other designated loop sequence for a distance of at least $161 \mathrm{~km}$ (100 miles). In a typical accelerated three-month reliability test, the drive sequence will accumulate a total of $18,508 \mathrm{~km}(11,500 \mathrm{mi})$. All activities are logged, including fuel delivered, AC energy input, malfunctions, and other notable events in the reliability test drive log.

After the end of three months of reliability testing, calculate the fuel economy of the vehicle by dividing the total distance driven by the sum of the volume of fuel used and the electrical equivalent energy used for each test. Calculate separate fuel economy values for urban and freeway tests. Determine liquid fuel usage from measurements collected by the fuel flow meter. Determine the electrical equivalent by recording the AC grid energy used to recharge the battery after each driving test and converting to a fuel equivalent based on the SAE J2711 procedure, as described in the energy 
efficiency calculation methods discussed for Performance Characterization.

After the reliability trials the designated driver completes a thorough subjective evaluation of the driving characteristics of the vehicle during the test period. The driver evaluation includes questions regarding vehicle handling, steering, braking, and ability to conform to traffic conditions, as well as overall driver comfort and confidence.

\subsection{Fleet Test Procedure}

The final aspect of the vehicle evaluation is integration into the SCE fleet for at least one year.

Working with SCE's Transportation Services Department (TSD) and its clients, the EVTC selects a fleet mission suitable to the vehicle's capabilities. The site and drivers are evaluated to ensure that the mission is compatible with the vehicle and there are drivers willing to undergo training. Three sites are selected and ranked according to their preference. Two sites will be backups, and both vehicles will preferably go to the same, preferred site. The trained drivers understand the vehicle operation and know to take the vehicle's operation into consideration while performing their duties.

As described previously, record all nameplate data, and serial numbers for the vehicle and all test equipment will be recorded. Also note the version of software and hardware and any component changes since the performance characterization or fleet tests.

Log all fuel usage and the odometer reading at fill-ups and electrical AC energy usage if a plug-in.

The baseline test should be completed within thirty days of the start of the fleet test deployment, and reference performance tests are conducted on a 16095 $\mathrm{km}$ (10,000 mile) or semi-annual basis thereafter until the end of the test period. The vehicles are evaluated less frequently during this component of the vehicle evaluation process in order to minimize the interference with fleet operations. The RPT is the same as described for the Reliability Procedures; including performance tests, EV range test, battery test, and HEV mode drive tests.

The vehicles will be driven as required each workday in fleet operations. The vehicle is fueled as needed and plugged into the electrical grid at the end of each workday. All activities, fuel delivered, AC energy input, malfunctions, and other notable events are logged. Any malfunctions are reported as soon as possible. The fleet trials continue for one year, unless otherwise restricted. At the end of fleet testing, the fuel economy of the vehicle will be calculated by dividing the total distance driven by the sum of the volume of fuel used and the electrical equivalent energy used for each test, following the SAE J2711 guidelines and conversion factors described previously. As fuel economy is drive cycle dependent, the values calculated will be specific to the fleet operation under which it is placed.

The operator evaluates the vehicle gages and controls as described previously to ensure continuing function and accuracy. The driver or drivers who used the vehicle during the fleet testing will take a thorough subjective survey of the vehicle. This survey evaluates the vehicles' handling, steering, braking, ability to conform to traffic, and overall driver comfort and confidence.

\section{CONCLUSION}

The SCE procedures allow for thorough evaluation of plug-in hybrid-electric vehicles for utility fleet applications. These test procedures are designed to improve understanding of vehicle performance, reliability, operation, and impact to the electric utility system, as well as to ensure safe and efficient operation.

\section{REFERENCES}

[1] EPRI, "Test Profile Development for the Evaluation of Battery Cycle Life for Plug-In Hybrid Electric Vehicles," EPRI, Palo Alto, CA: 2003, 1002228, Mar 2004.

[2] USABC, "Electric Vehicle Battery Test Procedures Manual Revision 2,” DOE/ID-10479, Rev. 2, Jan 1996.

[3] National Electric Vehicle Infrastructure Working Council, "Recommendations for Electric Vehicle Charging," EPRI, Palo Alto, CA, Oct 1997.

[4] SAE, "J2711, Recommended Practice for Measuring Fuel Economy and Emissions of HybridElectric and Conventional Heavy-Duty Vehicles," SAE, 09-01-2002.

\section{AUTHOR}

Jordan W. Smith, P.E.

Mr. Smith has been with Southern California Edison's Electric Transportation Division since 1996. Currently he is Lead Engineer for the Electric Vehicle Technical Center, renowned for its work in vehicle, energy storage, and utility system evaluations. He has been responsible for conducting efficiency assessments, developing test standards, and evaluating distributed energy systems. A specialist in non-road and hybrid-electric technology, he led the first project to successfully demonstrate a plug-in hybrid-electric conversion of a utility fleet trouble truck, which was capable of operating in allelectric mode, had electro-hydraulic operation, and had mobile distributed power capabilities. Mr. Smith received a B.S. degree in mechanical engineering and an M.S. degree in engineering management from California State Polytechnic University. $\mathrm{He}$ is a California licensed professional engineer.

Heavy -Duty Hybrid Veicle Evaluations in Utility Fleet Applications 